\title{
FAKTOR-FAKTOR YANG MEMPENGARUHI NILAI TAMBAH USAHA TERNAK SAPI DI DESA TUMARATAS KECAMATAN LANGOWAN BARAT
}

\author{
E. Wantasen* dan U. Paputungan
}

Fakultas Peternakan Universitas Sam Ratulangi Manado, 95115

\begin{abstract}
ABSTRAK
Tujuan penelitian ini adalah mengetahui besarnya nilai tambah dan faktor faktor yang mempengaruhi nilai tambah usaha peneliharaan ternak sapi di Desa Tumaratas Kecamatan Langowan barat. Data primer diperoleh dari 100 rumah tangga peternak sampel dengan menggunakan daftar pertanyaan. Sampel peternak ditentukan secara purposive sampling dengan kriteria memiliki minimal satu ekor sapi dan pernah menjualnya. Analisis data dilakukan secara deskriptif dan kwantitatif menggunakan fungsi regresi linier berganda. Hasil penelitian menunjukkan bahwa semakin besar skala pemilikan ternak sapi semakin besar nilai tambah yang diperoleh. Rata rata nilai tambah per unit ternak sapi sebesar Rp. 4.435.543 per tahun. Secara parsial bahwa faktor faktor biaya inseminasi, tenaga kerja keluarga pada usaha ternak sapi dan biaya kawin alami berpengaruh positif terhadap nilai tambah ternak sapi sedangkan tenaga kerja keluarga pada usahatani tanaman pangan berpengaruh negatif terhadap nilai tambah ternak sapi
\end{abstract}

Kata kunci : nilai tambah, biaya inseminator, biaya kawin alami, tenaga kerja keluarga.

*Korespondensi (Corresponding Author)

Email: erwinwantasen@yahoo.co.id

\section{ABSTRACT}

FACTORS INFLUENCING VALUE ADDED OF CATTLE BUSINESS AT TUMARATAS VILLAGE DISTRICT OF LANGOWAN BARAT. The objective of this research was to know value added and factors influencing value added on cattle business at Tumaratas Village district of Langowan Barat, Minahasa Regency. Primary data were collected from 100 samples of households by using questionnaire. Respondents were purposively selected by considering farmers at least has one cattle and ever sold it out. . Data were analyzed by using descriptive and quantitative analysis by using multiple regression model. Study results indicated that the more cattle owned by household the more value added of cattle achieved. The average of value added per animal unit was IDR 4,434,543/years. Partially factors of inseminator cost, cost of natural mating and household labor on cattle business had positive affect on value added of cattle while household labor on food crops business had negative impact on value added of cattle.

Key words: Value added, inseminator cost, natural mating cost, household labor

\section{PENDAHULUAN}

Produksi daging sapi dalam negeri yang belum mampu memenuhi permintaan terkait dengan adanya berbagai 
permasalahan dalam pengembangan sapi potong. Beberapa permasalahan tersebut adalah: 1) usaha bakalan atau calf-cow operation kurang diminati oleh pemilik modal karena secara ekonomis kurang menguntungkan dan dibutuhkan waktu pemeliharaan yang lama, 2) adanya keterbatasan pejantan unggul pada usaha pembibitan dan peternak, 3) ketersediaan pakan tidak kontinu dan kualitasnya rendah terutama pada musim kemarau, 4) pemanfaatan limbah pertanian dan agroindustri pertanian sebagai bahan pakan belum optimal, 5) efisiensi reproduksi ternak rendah dengan jarak beranak (calving interval) yang panjang, 6) terbatasnya sumber bahan pakan yang dapat meningkatkan produktivitas ternak dan masalah potensi genetik belum dapat diatasi secara optimal serta 7) gangguan wabah penyakit (Isbandi, 2004 ; Kariyasa, 2005; Subagyo, 2009 ; Sarma dkk 2011; Hoddi dkk, 2011)

Ternak sapi adalah salah satu jenis ternak yang memiliki potensi untuk dikembangkan di Sulawesi Utara. Ternak sapi memiliki peran dalam penyediaan bahan makanan berupa daging, sebagai salah satu sumber pendapatan bagi rumah tangga petani peternak di pedesaan dan sumber tenaga ternak selain sebagai penyedia lapangan kerja , tabungan dan sumber devisa yang potensil serta untuk perbaikan kualitas tanah. Ternak Sapi di
Sulawesi utara telah dijadikan sebagai ternak andalan yang ditetapkan pemerintah daerah dalam rangka menigkatkan pertumbuhan ekonomi daerah khususnya dari subsektor Peternakan. Jumlah populasi ternak sapi di Sulawesi Utara pada tahun 2015 adalah 109.957 ekor dan jumlah populasi terbanyak terdapat di wilayah Kabupaten Minahasa sebanyak 24.730 ekor (BPS, Sulut. 2016). Kecamatan Langowan Barat adalah wilayah dengan populasi ternak sapi yang paling banyak diantara 22 wilayah Kecamatan di Kabupaten Minahasa dengan jumlah ternak sapi sebesar 3.712 ekor yang terdiri atas 683 ekor sapi jantan dan 3.029 ekor sapi betina. Kecamatan Langowan Barat memiliki 10 desa dimana desa Tumaratas memiliki populasi sapi terbanyak dibandingkan desa lainnya yaitu 786 ekor. Untuk meningkatkan jumlah pemilikan ternak maka peternak menggunakan teknologi inseminasi buatan (IB) dan sistim kawin alam dengan menggunakan jenis pejantan unggul (Hadi dan Ilham, 2002; Johnson, 2011; Maina et al, 2012). Inseminasi buatan masih dianggap sebagai teknologi untuk meningkatkan populasi sapi oleh petani diwilayah Kecamatan Langowan Barat. Bibit sapi jantan yang sangat diminati di daerah penelitian adalah sapi peranakan ongole (PO) dengan alasan sapi tersebut memiliki kemampuan fisik yang baik 
untuk bekerja di lahan pertanian. Tujuan peternak menggunakan teknologi inseminasi adalah agar ternaknya memperoleh peningkatan nilai tambah karena harga jual ternak meningkat, kemampuan bekerja ternak sapi semakin tinggi sehingga harga sewanya meningkat dan produksi kotoran untuk dapat diolah menjadi pupuk organik semakin banyak. Masalah yang dihadapi oleh peternak sapi di Desa Tumaratas Kecamatan Langowan Barat adalah terbatasnya tenaga inseminator dan ternak sapi jantan unggul sehingga berdampak pada lambatnya perkembangan ternak sapi milik peternak. Untuk mengatasi masalah tersebut peternak bersedia memberi tambahan biaya kepada inseminator agar segera menginseminasi ternaknya yang sudah harus dikawinkan. Karena itu Penelitian ini bertujuan untuk mengetahui seberapa jauh biaya inseminasi dan biaya kawin alam mempengaruhi nilai tambah ternak sapi di Desa Tumaratas Kecamatan Langowan Barat.

\section{METODE PENELITIAN}

\section{Lokasi dan Waktu Penelitian}

Pengumpulan data penelitian dilakukan di Desa Tumaratas Kecamatan Langowan Barat pada bulan Februari April 2017. Desa Tumaratas dipilih sebagai daerah penelitian karena memiliki populasi ternak sapi terbesar di
Kecamatan Langowan Barat. Peternak sapi di wilayah ini sudah menerapkan insemiansi dan kawin alami serta mengolah kotoran sapi menjadi pupuk kompos.

\section{Metode Penentuan Sampel dan Pengumpulan Data}

Jumlah sampel dalam penelitian ini adalah 100 peternak yang dipilih secara purposive random sampling (Kuncoro, 2003) dengan pertimbangan memiliki ternak sapi betina dewasa minimal 1 ekor, memiliki lahan usahatani baik berupa lahan yang disewa atau milik sendiri, meimiliki pengalaman beternak sapi minimal 3 tahun, melakukan proses inseminasi dan kawin alami dan pernah menjual sapi. Pengumpulan data primer dan data sekunder dilakukan dengan teknik survey untuk mendapatkan informasi yang dibutuhkan berkaitan dengan tujuan penelitian dengan menggunakan daftar pertanyaan. Informasi yang bersifat informal dilakukan dengan kepala desa dan kepala pos kesehatan hewan Kecamatan Langowan Barat untuk memastikan kebenaran informasi yang diperoleh dari responden peternak sapi.

\section{Analisis Data}

Analisis data menggunakan metode deskriptif dan kuantitatif. Analisis deskriptif dilakukan untuk mengetahui karakteristik responden sedangkan analisis 
kuantitatif digunakan untuk mengetahui faktor yang mempengaruhi nilai tambah ternak sapi. Model analisis regresi linier berganda digunakan untuk mengetahui pengaruh biaya inseminator, biaya kawin alam tenaga kerja keluarga pada usaha ternak sapi dan tenaga kerja pada usahatani tanaman pangan (Gujarati, 2003) :

$\mathrm{Y}=\mathrm{bo}+\mathrm{b} 1 \mathrm{X} 1+\mathrm{b} 2 \mathrm{X} 2+\mathrm{b} 3 \mathrm{X} 3+\mathrm{b} 4 \mathrm{X} 4$

Dimana :

$$
\begin{aligned}
& \mathrm{Y}=\text { Nilai tambah ternak sapi } \\
& \text { (Rp/tahun/peternak) } \\
& \mathrm{X} 1=\text { Biaya inseminator } \\
& \text { (Rp/tahun/peternak) }
\end{aligned}
$$

$$
\begin{aligned}
& \mathrm{X} 2=\text { Biaya kawin alam } \\
& \text { (Rp/tahun/peternak) } \\
& \mathrm{X} 3=\text { Tenaga kerja keluarga pada } \\
& \text { usaha ternak sapi } \\
& \text { (HOK/tahun/peternak) } \\
& \text { X4 }=\text { Tenaga kerja keluarga pada }
\end{aligned}
$$

\begin{tabular}{|c|c|c|c|c|}
\hline Variabel & Kategori & Jumlah & Persentasi & Rata rata \\
\hline Pemilikan lahan & $0,15-0,68$ & 53 & 53 & 0,83 \\
\hline \multirow[t]{2}{*}{ (Ha) } & $0,69-1,27$ & 29 & 29 & \\
\hline & $>1,27$ & 18 & 18 & \\
\hline \multirow[t]{3}{*}{ Lahan garapan $(\mathrm{Ha}$} & $0,1-0,69$ & 69 & 69 & 0,77 \\
\hline & $0,70-1,27$ & 19 & 19 & \\
\hline & $>1,27$ & 12 & 12 & \\
\hline \multirow[t]{3}{*}{ Jumlah Sapi (ST) } & $\leq 5$ & 90 & 90 & 3,35 \\
\hline & $5-10$ & 6 & 6 & \\
\hline & $>10$ & 3 & 3 & \\
\hline Anggota RT & $2-4$ & 75 & 75 & 3,65 \\
\hline \multirow[t]{2}{*}{ (Orang) } & $5-7$ & 16 & 19 & \\
\hline & $>7$ & 9 & 9 & \\
\hline \multirow[t]{3}{*}{ Umur } & Usia Produktif & & 7035 & 2,37 \\
\hline & Usia tidak & & 29,65 & 1,28 \\
\hline & Produktif & & & \\
\hline \multirow[t]{4}{*}{ Pndidikan } & Elementary & 21 & 21 & \\
\hline & Secondary school & 37 & 37 & \\
\hline & High school & 35 & 35 & \\
\hline & University & 7 & 7 & \\
\hline
\end{tabular}

\section{HASIL DAN PEMBAHASAN}

\section{Karakteristik responden}

Hasil penelitian pada Tabel 1 menunjukkan bahwa luas penguasaan lahan oleh peternak sapi di Desa Tumaratas adalah 0,83 Ha sedangkan lahan garapan sebesar 0,77 Ha.

Tabel 1. Karakteristik Responden 
Lahan yang dimiliki relatif kecil yang diperoleh dari warisan orang tua. Besar kecilnya lahan yang diwariskan orang tua tergantung pada jumlah anak yang dimiliki karena lahan harus dibagi bersama seluruh anggota keluarga. Lahan yang tidak digarap digunakan peternak untuk memberi makan ternak sapinya.Karena itu peternak menyisakan lahannya untuk pertumbuhan rumput hijauan pakan ternak sapi yang dimiliki. Lahan garapan ditanami dengan kacang merah, tomat, cabe, bawang merah, jagung. Secara umum peternak sapi memiliki pendidikan formal meskipun beberapa responden tidak lulus pendidikan sekolah dasar. Sebanyak $35 \%$ peternak memiliki pendidikan sekolah menengah atas, $37 \%$ berpendidikan SMP , 21\% lulus SD dan sebanyak $7 \%$ memiliki pendidikan tinggi.Hal ini menunjukkan bahwa sebagian besar peternak memiliki pendidikan menengah. Hasil penelitian sejalan dengan Wantasen dkk (2014) bahwa $42 \%$ peternak di Desa Poyowa Besar Kota Kotamobagu memiliki pendidikan SMA dan sederajatnya. Hasil penelitian menunjukkan bahwa rata rata pemilikan ternak sapi per peternak sebesar 3,35 Satuan Ternak (ST). Hal ini disebabkan karena keterbatasan lahan peternak sebagai sumber pakan ternak sapi. Rata rata jumlah anggota rumah tangga peternak 3,65 orang.Hal ini disebabkan peternak lebih berkeinginan untuk berpisah dengan orang tua setelah menikah sedangkan peternak yang tidak produktif biasanya tinggal bersama anak dan cucu mereka (Wantasen et al, 2012). Sebagian besar anggota keluarga tergolong pada usia produktif $(70,45 \%)$ dan usia tidak produktif $(29,55 \%)$. Secara keseluruhan keluarga peternak memiliki anggota keluarga yang berpotensi untuk mengelola usaha ternak sapi.

\section{Nilai Tambah Ternak Sapi}

Peternak memperoleh nilai tambah dari sapi karena sapi dapat membantu bekerja mengolah lahan usahatani dan mengangkut hasil usaha pertanian, sapi dapat menghasilkan kotoran yang dapat dijadikan pupuk kandang, sapi jantan dapat digunakan sebagai pejantan, dan sapi menjadi tabungan rumah tangga yang dapat di jual sewaktu peternak membutuhkan biaya tambahan untuk kebutuhan mendesak seperti biaya pendidikan anak dan biaya kesehatan. Gambar 1 menunjukkan bahwa setiap unit ternak sapi memberikan nilai tambah untuk masing-masing kelas pemilikan ternak $\leq 5 \mathrm{UT}, 5-10 \mathrm{UT}$ dan $>10 \mathrm{UT}$ sebesar Rp.4.372.411/UT/Tahun, Rp.4.666.666/UT/Tahun dan Rp.5.250.000/UT/Tahun. 


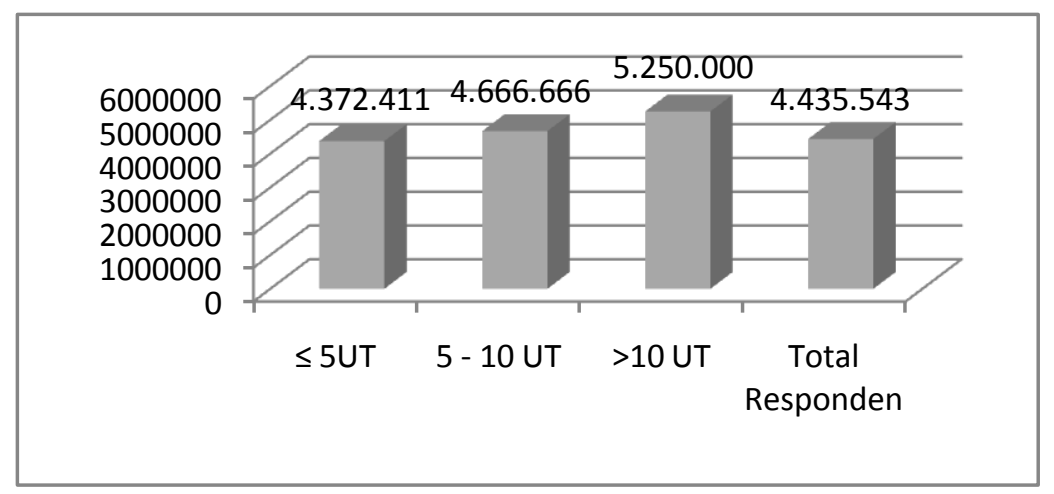

\section{Gambar 1. Nilai Tambah Ternak Sapi (Rp/ST/Tahun)}

Rata-rata pemilikan ternak sapi oleh keseluruhan peternak adalah 3,35 UT sehingga nilai tambah per unit ternak diperoleh sebesar Rp. 4.435.543/UT/tahun. Nilai tambah ternak meningkat dengan peningkatan skala pemilikan karena perbedaan penampilan fisik atau kecantikan ternak dan umur ternak. Fenomena di daerah penelitian menunjukkan bahwa peternak skala yang lebih rendah akan menjual sapinya yang masih produktif karena keterbatasan lahan untuk memberi pakan hijauan. Keterbatasan lahan menyebabkan kuantitas pakan berkurang sehingga pertumbuhan ternak kurang baik dan mengurangi kecantikan sapi yang pada akhirnya akan mengurangi peningkatan nilai tambah sapi. Penelitian Syafril dan Ibrahim (2006) bahwa ternak sapi potong memberikan tambahan pendapatan rumah tangga sebesar Rp.3.188.725/UT/tahun, menunjukkan nilai tambah ternak sapi di
Desa Tumaratas lebih tinggi karena pemanfaatan ternak di wilayah penelitian sebagai tenaga kerja yang oleh masyarakat dipandang lebih tinggi nilainya dibanding sebagai ternak potong.

\section{Faktor Faktor Yang Mempengaruhi}

Nilai Tambah Ternak Sapi

Hasil analisis regresi berganda yang ditampilkan pada Tabel 2 menunjukkan secara bersama sama variabel biaya inseminator, biaya kawin alam, tenaga kerja keluarga pada usaha ternak sapi, tenaga kerja keluarga pada usahatani tanaman pangan berpengaruh pada nilai tambah ternak sapi sebesar 75,34\% (Adj $R^{2}=0,7534$ ). Variabel yang secara signifikan meningkatkan nilai tambah ternak sapi $(\mathrm{P}<0,05)$ adalah biaya inseminator $(51,72)$, biaya kawin alam $(24,37)$ dan tenaga kerja keluarga pada usaha ternak sapi $(1389573,6)$. Sedangkan variabel tenaga kerja keluarga pada tanaman pangan berpengaruh negatif 
Tabel.2 Faktor Yang Mempengaruhi Nilai Tambah Ternak Sapi

\begin{tabular}{|c|c|c|c|}
\hline Variabel & Koefisien & t value & Probability \\
\hline Konstan & -1256733 & $-3,533 * *$ & 0,0454 \\
\hline Biaya Inseminator & 51,72 & $4,279 * *$ & 0,0334 \\
\hline Biaya kawin alam & 24,37 & $7,337 * * *$ & 0,0002 \\
\hline $\begin{array}{l}\text { Ternaga } \quad \text { kerja } \\
\text { keluarga pada ternak } \\
\text { sapi }\end{array}$ & 1389573,6 & $5,0034 * * *$ & 0,0065 \\
\hline $\begin{array}{l}\text { Tenaga kerja } \\
\text { keluarga pada usaha } \\
\text { tanaman pangan }\end{array}$ & $-345700,8$ & $1,8775^{*}$ & 0,0689 \\
\hline Adj $R^{2}$ & & & 0,7534 \\
\hline F value & & & 0,0000 \\
\hline
\end{tabular}

${ }^{* * *}=$ signifikan pada $\alpha=0,01$

** $=$ Signifikan pada $\alpha=0,05$

$*$ Signifikan pada $\alpha=0,10$

terhadap nilai tambah ternak. Hasil penelitian sejalan dengan Wantasen (2014) dan Asmah (2011) bahwa faktor inseminasi dan tenaga keluarga berpengaruh terhadap pendapatan usaha ternak sapi dan nilai tambah ternak sapi. Biaya inseminator berpengaruh terhadap nilai tambah ternak sapi karena adanya biaya inseminator berarti peternak telah melakukan proses inseminasi buatan (IB) dengan bibit sapi peranakan ongole (PO) sehingga memperoleh tambahan pedet sapi setiap tahun. Biaya kawin alam berpengaruh terhadap nilai tambah ternak sapi karena kawin alam menjadi alternatif pilihan peternak bila bibit sapi PO melalui IB tidak tersedia saat ternaknya siap untuk dikawinkan sehingga peternak akan mencari pejantan yang akan dikawinkan dengan ternak betina miliknya.

Penggunaan tenaga kerja keluarga berpengaruh terhadap nilai tambah ternak sapi karena setiap hari peternak mengurus ternaknya dengan baik seperti memberi makan dan minum, memandikan, mengawinkan, mengolah kotoran sapi, menjual, memberi obat jika sakit sehingga ternak sapi memiliki penampilan fisik yang baik sebagai tenaga kerja dan kotorannya digunakan sebagai pupuk dilahan usahatani sehingga nilainya semakin tinggi. Tenaga kerja keluarga berpengaruh negative terhadap nilai tambah karena produksi usaha tani seperti tomat dan bawang merah yang dimiliki peternak membutuhkan banyak tenaga kerja pada saat saat tertentu sehingga mengurangi ketersediaan tenaga kerja pada usaha ternak , akibatnya perhatian 
terhadap ternak sapi berkurang karena supply makanannya berkurang.

\section{KESIMPULAN}

Rata rata nilai tambah per unit ternak sapi sebesar Rp. 4.435.543 per tahun. Secara parsial bahwa faktor faktor biaya inseminasi, tenaga kerja keluarga pada usaha ternak sapi dan biaya kawin alami berpengaruh positif terhadap nilai tambah ternak sapi sedangkan tenaga kerja keluarga pada usahatani tanaman pangan berpengaruh negatif terhadap nilai tambah ternak sapi

\section{DAFTAR PUSTAKA}

BPS. Sulut, 2016. Sulawesi Utara Dalam Angka . Kantor Statistik Sulawesi Utara, Manado

Isbandi. 2004. Pembinaan kelompok petani ternak dalam usaha ternak sapi potong. Jurnal Indonesia Trop. Anim. Agric. 29(2): 106 114.

Kariyasa, K. 2005. Sistem integrasi tanaman ternak dalam perspektif reorientasi kebijakan subsidi pupuk dan peningkatan pendapatan petani. Jurnal Analisis Kebijakan Pertanian 3(1): 68-80.

Subagyo, I. 2009. Potret Komoditas Daging Sapi. Economic Review $217: 1-7$

Sarma. P.K, and J.U Ahmed. 2011. An Economic Study of Small Scale Cattle Fattening Enterprise of Rajibari District. J Bangladesh Agriculture 9(1):141-146
Hoddi, A.H., M.B. Rombe, dan Fahrul. 2011 Analisis Pendapatan Peternak Sapi Potong Di Kecamatan Tanete Rilau Kabupaten Barru. Jurnal AGRIBISNIS X (3): 98-109

Hadi, P.U. dan N. Ilham. 2002. Problem dan Prospek Pengembangan Usaha Pembibitan Sapi Potong di Indonesia. Jurnal Penelitian dan Pengembangan Pertanian 21(4): 148-157.

Johnson. 2011. Impact of Artificial Insemination on Productivity - A Study. Thesis. School of Good Governance and Policy Analysis. Bhopal Madya Pradesh

Maina I.N, I.U Leonhäuser and S Bauer. 2012. Adoption of improved agricultural technologies among smallholder farm households in Nakuru District, Kenya. Journal of Agricultural Extension and Rural Development 4(8) : 147-163,

Kuncoro, M. 2003. Metode Riset Untuk Bisnis dan Ekonomi, Bagaimana Meneliti dan Menulis Thesis. Penerbit Erlangga. Jakarta

Syafril dan I. Ibrahim. 2006. Kontribusi pendapatan usaha tani ternak sapi terhadap Pendapatan usaha tani di Kota Padang. Jurnal Ilmullmu Peternakan IX(2): 130-137.

Wantasen E., B. Hartono, N Hanani, V.V.J. Panelewen.2012 Household Economic Behavior of Traditional Cattle Farmers in Utilizing Artificial Insemination Technology: A Case Study in Village of Kanonang III, Minahasa Regency of Indonesa. J. Agric. Food. Tech. 2 (8) :141-152

Wantasen E., F.H. Elly , N.M. Santa. 2014 The Analysis of Semi Intensive Native Chicken Farming In Rural 
Communities. J. Indonesian. Trop.

Anim .Agric. 39 (2): 126-133

Wantasen E. dan B. Hartyono. 2014.

Analisis Faktor-Faktor Yang Mempengaruhi Ekonomi Rumah

Tangga Peternak Sapi Peranakan

Ongole Kabupaten Minahasa,

Prosiding. Optimalisasi Sumber

Daya Lokal Pada Peternakan

Rakyat Berbasis Teknologi.

Fakultas Peternakan Universitas

Hasanudin Makassar, 9-10 Oktober

2014:252-261 